THE THREE “I”'s WEIGHING UPON JAPANESE OVERSEAS

EDUCATION: A STUDY OF THE CHALLENGES

FACING SUPPLEMENTARY SCHOOLS

\title{
MIZUNO NORIHITO
}

Global Studies Program, Akita International University, Akita, Japan

\begin{abstract}
Supplementary schools are one of the educational institutions for overseas Japanese children, along with full-time Japanese schools and the overseas branch campuses of Japanese private schools. The supplementary schools are generally open at the weekend, except for some cases. The original and primary educational objective of such schools is to help the overseas Japanese children to maintain or improve their mother tongue (Japanese) and adjust themselves smoothly to the Japanese school environment after returning home. More Japanese parents were inclined to send their children to local schools in North America and Western Europe or international schools, slightly more than 50 percent of overseas Japanese students of compulsory education age (6-15 years old) go to those different types of Japanese-speaking schools, and nearly half of them study at supplementary schools. This shows that the supplementary schools have significant weight with Japanese overseas education today. However, for the school management, to offer a Japanese standard of quality education overseas is by no means an easy task, and this article argues that the schools are faced with a series of problems by categorizing them into the three "I"s -- insufficiency, instability, and inconsistency.

KEYWORDS: Japanese Education, Overseas Education \& Educational Policy
\end{abstract}

Received: Dec 15, 2017; Accepted: Jan 05, 2018; Published: Feb 14, 2018; Paper Id.: IJESRFEB201812

\section{INTRODUCTION}

For over half a century, the population of Japanese residents overseas has consistently increased. The catastrophic defeat in the Second World War expunged all the overseas Japanese communities, and over six million Japanese, including more than three million military personnel, in the colonies and the wartime occupied territories were repatriated. (Sasaki, 3) Along with the revival of the Japanese economy in the postwar period, however, the number of overseas Japanese residents started to increase again. The so-called postwar economic miracle from the late 1950s until the 1973 oil crisis and the subsequent moderate economic growth throughout the 1970s and 1980s promoted the overseas advance of Japanese business and an increase in the overseas Japanese population, and the number of overseas children has also continued to increase (Kaigai ziryu hojin jinko tokei, 20, 26, 40).

The Japanese government, businesses and citizens overseas have acted in concert to provide education for their juvenile compatriots living in a foreign land, in accordance with the education curriculum and system of the home country. The Ministry of Education, Culture Sports, Science and Technology (MEXT) exercise jurisdiction over overseas education in close cooperation with the Ministry of Foreign Affairs (MOFA), which recognizes education as one of the primary concerns for overseas Japanese residents (Gaimusho). Other governmental and nongovernmental organizations at home and abroad, such as Tokyo Gakugei University, Japan Overseas Educational Services, and Japanese associations 
have also been involved in overseas education. As a result, in order to have their children educated in their mother tongue (Japanese), Japanese parents overseas have three options i.e. full-day Japanese schools (Nihonjin gakko) students go from Monday to Friday as those of the same age do in Japan. Another is a supplementary school (hoshu jugyoko), and the branch schools of Japanese private schools located in Japan (CLARINET).

Such official and unofficial efforts have certainly contributed to the enrichment of Japan's overseas education, which is faced with various challenges today. Some of them are not new but chronic, and the government, overseas Japanese schools, and organizations and individuals concerned have experienced them for a long time. Others have recently cropped up because of the change of environments surrounding the overseas education at home and abroad. This article focuses on the supplementary schools. The schools are; generally speaking, open at the weekend except for some cases, and the primary objective is to help the overseas children maintain or improve their mother tongue and to be able to adjust themselves smoothly to the Japanese school environment after returning home. Schools, nowadays are faced with various problems, which can be categorized into three "I"s -- insufficiency, instability, and inconsistency.

\section{OVERSEAS JAPANESE EDUCATIONAL INSTITUTIONS}

The number of Japanese citizens overseas, including both permanent and "long (over three-months) stay" residents, has been steadily increasing over the past three decades (Kaigai ziryu hojin jinko tokei, 20). The report of MOFA shows that this figure had reached 1,338,477 in October 2016. As its breakdown shows, 468,428 (35\%) are permanent residents, and $870.049(65 \%)$ are long stay residents. 36.7\% of the total number live in North America, followed by Asia $(29.3 \%)$ and Western Europe (15.9\%). A salient phenomenon in recent years has been a significant increase in the Japanese population in Asia-Pacific region and Eastern Europe, though it has been slightly and consistently decreasing in China since 2013. The MOFA reports show that 392.216 and 118.452 live in Asia and the Pacific region, respectively. Despite the financial crises and economic downturns starting with the Lehman Shock in 2008, the number of Japanese residents in the United States and Western Europe momentarily decreased in 2009, but it has steadily been increasing and remained at a high level. Nearly 500,000 live in North America, mostly in the United States, and more than 200,000 live in Western Europe (Kaigai ziryu hojin jinko tokei, 22).

The number of Japanese children overseas of compulsory education age (6-15 years old) has simultaneously continued to increase for at least over the past twenty years. It would not be perhaps surprising that an increasing trend in overseas Japanese children of school age has more or less been parallel with the increase of Japanese residents overseas. In the post-Cold War period, precisely speaking, the overseas child population has twice gone through a slight decline in 1996 and 2011. It is perhaps due to domestic and external economic causes. The population of overseas Japanese children reached its highest number $(67,322)$ in 2010, declined to 64, 950 in 2011, and has reached 79, 251 in 2016 (Kaigai zairyu hojin jinko tokei, 44). As a recent tendency, the ratio of junior high aged children has continued to increase gradually from less than 24 percent to over 27 percent since 2004 (Kaigai de manabu Nihon no kodomo, 2).

Living with their children of school age overseas, Japanese parents have to make a decision on what types of educational institutions should be chosen for their education unless homeschooling is preferred. Parents would simply choose to send their children to a local school whose learning language is the local language. Available nearby or affordable financially, international schools would be another option. Otherwise, parents would choose other types of schools in which their children can learn in Japanese. Parents would choose any of those schools in consideration of various factors, such as their children's future pass and financial leeway; language also weighs heavily in their decision. 
The number of Japanese parents, who choose either of the non-Japanese speaking schools has in fact been increasing in recent years. According to the 2016 MEXT annual report, 37,803 out of 78,312 children of compulsory education age go to "local schools" and "others," which include international schools (Kaigai de manabu Nihon no kodomo, 1). This is equivalent to $48 \%$ of the whole number of compulsory school age children living outside Japan (Kaigai de manabu Nihon no kodomo, 1). Some parents, especially those who live in developed Western countries, seem to be willing to choose either of the non-Japanese speaking schools for their children to let them acquire foreign language skills such as English and other major European languages (Kikyusen, 2006, p. 201; 2007, p. 206; 2007, p. 215). They expect those schools to help their children acquire not only languages but also competencies for a globalized world. For other parents, the non-Japanese speaking schools would be inevitable choices because of the absence of Japanese-speaking schools nearby or within commutable distance.

Parents, who want to send their children to Japanese-speaking schools also, have multiple options. Children's smooth adjustment to and survival at school after returning to Japan is in fact a worry, broadly shared among Japanese parents overseas, and the upkeep or brush-up of overseas children's verbal aptitude is a matter of grave concern. Even those who are permanent or semi-permanent residents overseas, would wish their children to keep up or at least be familiar with the language of their motherland. MEXT authorizes Japanese-speaking overseas educational institutions conforming to the domestic school regulations as "overseas educational institutions (zaigai kyoiku shisetsu)." There are three types of authorized schools i.e. Japanese schools (Nihonjin gakko), private overseas schools whose parent institutions are in Japan (shiritsu zaigai kyoiku shisetsu), and supplementary schools open at the weekend, or after students come back from nonJapanese schools (hoshu jugyoko) (CLARINET).

Available within a commutable distance or financially affordable, Japanese schools would be a choice for the parents who want their children to study in Japanese. This is the full-time institution, which offers equivalent programs to the schools at home in accordance with the official curriculum guidelines determined by MEXT. After the Second World War, the first Japanese school was founded in Bangkok in 1956 (CLARINET), and as of April 2016, 89 full-time Japanese schools are located in 501 countries and areas, and 20,615 elementary and junior high school students are registered in these institutions (Kaigai de manabu Nihon no kodomo, 4). This means that, slightly more than $26 \%$ of overseas Japanese children of compulsory education age study at this full-day school in their mother tongue, from Monday to Friday. The schools vary in enrollment from single digits to over three thousand all over the world. A steering committee composed of representatives of local Japanese organizations, such as a Japanese association (Nihonjinkai) and companies and the parents of enrolled students usually manage the school. The school's legal status depends on the legislative system of the country in which each institution is located (CLARINET). In the Japanese compulsory education system, students are provided with free textbooks at home. Overseas Japanese elementary and junior high school students at the full-day schools can also receive the same service abroad and study with the same textbooks used in Japan (Kaigai de manabu Nihon no kodomo, 6). Article 26 of the Japanese Constitution enacts gratuitous compulsory education (Nihonkoku kenpo). Nevertheless, parents have to bear a considerably high tuition burden to send their children to full-day schools overseas, not subject to Japanese national sovereignty. For example, in the case of elementary schools, the annual tuition of the Japanese School of New York is over 93,000 US dollar and is more for the junior high school program. The monthly tuition of the Japanese School of New Delhi is 22,000 rupee (approximately 340 US dollar) (The Japanese School of New York; Japanese School New Delhi) the graduates of the full-time junior high schools were given a qualifying certificate for high schools at home by MEXT (CLARINET). As minor cases, some full-days schools have kindergarten programs, and the Shanghai Japanese 
School, with the largest enrollment in two locations is the only full-day school, which has a high school program (Kikyusen, 2011, p. 228). The graduates of this high school are also to be given qualifying certificates for colleges at home (Kaigai de manabu Nihon no kodomo, 2016, p. 3).

Some Japanese private schools have overseas branches or sister schools, which can be another option for the parents who desire to give their children full-time Japanese speaking education. As of April 2016, there are eight private schools of this sort authorized or designated by MEXT, and about 1,200 students are enrolled in these institutions (Kaigai de manabu Nihon no kodomo, 2016, p. 3). Each school offers programs at various educational levels from kindergarten to high school. Those who completed the junior and senior high school programs at these schools are also given qualifying certificates for Japanese high schools and colleges at home. Some of them such as the Keio Academy of New York are escalator schools, and their high school graduates have the possibility to be admitted to prestigious private colleges without regular entrance examinations at home. The tuition at those overseas private schools includes boarding fees in some cases. It is even far more expensive than other overseas Japanese schools and even domestic private schools. For example, the annual tuition of Keio in New York costs 25,000 UD dollar (Keio), and that of Waseda Shibuya Senior High School in Singapore also costs 21,374 Singapore dollar (nearly 16,000 US dollar) (Waseda).

\section{SUPPLEMENTARY SCHOOLS}

Supplementary schools are another type of MEXT-authorized Japanese-speaking overseas educational institutions. The first supplementary school was founded in Washington, D.C. in 1958, and now 205 schools are located in 53 countries and regions. According to the statistics of April 2016, the total number of students enrolled in elementary and junior high school programs was 19,894, which accounted for slightly more than $25 \%$ of the overseas students of compulsory education age (Kaigai de manabu Nihon no Kodomo, 4, 2016). The number of enrollment ranges from single digits to over one thousand. The enrollment of the largest supplementary school named Asahi Gakuen in Los Angeles, including high school-aged children, comes up to 1,350 in four locations ( Rosu Anjerusu). There are two kinds of supplementary schools today. Most of the schools are opened at least 35 times per year, only on the weekend. Four schools located in Oman, Chennai, Guadalajara, and Dar es Salaam are exceptionally open five days a week, 175 times per year, after local or international schools are over. Those schools are called semi-full time schools (junzennichisei hoshu jugyoko) (Suenaga, p. 1).

Supplementary schools have some similarities to the full-time Japanese speaking schools. MEXT expects supplementary schools, as well as full-time schools, to follow or respect the Japanese official curriculum guidelines. All overseas children of compulsory education age have a right to receive free textbooks as their compatriots of the same age do at home, and the three Japanese schools basically use the same elementary and junior high school textbooks. The legal status of supplementary schools also depends on local legislative systems, and the management is usually entrusted to a steering committee, or a similar body, consisting of local Japanese organizations, companies and individuals (CLARINET). The parents whose children go to supplementary schools also pay tuition, which is much cheaper than that of full-time schools.

On the other hand, there are differences between supplementary and full-time schools. All overseas educational institutions, either full-time or supplementary, comply with or esteem the educational guidelines introduced by MEXT, but still have some freedom to make their own choices on what programs should be offered. As mentioned above, the full-time schools rarely have kindergarten or senior high school programs. Some of the private schools only offer senior high school 
programs. Moreover, supplementary schools also have different programs. Many offer only mathematics and Japanese language courses, but few others, including the semi-full time schools, offers social studies and science courses. Some have either (both) kindergarten or (and) senior high school programs, but others do not (CLARINET). As a matter of fact, however, the presence of various types of programs merely manifests the limitation of supplementary schools' capability to offer quality education for overseas Japanese children to survive at home.

\section{THE THREE "I"S IN SUPPLEMENTARY SCHOOLS}

The Japanese government takes the stance that; it should provide maximum support to enable overseas Japanese children to receive an education at least proximate to the domestic compulsory education. MOFA proclaims that overseas education should be up to the efforts of overseas Japanese residents themselves, stating that Japanese schools and supplementary schools are also institutions which the overseas residents have established and manage for the sake of the education of the children who accompanied them. MOFA further explains, "There is a common understanding that education belongs to the sovereignty of each country. Since overseas education is provided in foreign countries outside of the sovereignty of our country, it is impossible for the government to be directly involved and hence to execute compulsory education as it does at home"(Gaimusho). The aforementioned private overseas schools aside, MOFA defines Japanese and supplementary schools as what overseas residents have jointly established and managed. This never means, however, that the government is either indifferent to, or refuses to be engaged in overseas education, which MOFA recognizes as "one of the primary concerns for overseas nationals" (Gaimusho). It furthermore refers to the more profound significance of the improvement and enhancement of overseas education, as a necessary step towards the further success of Japanese overseas activities (Gaimusho). MEXT and MOFA have in fact been taking budgetary measures and providing a variety of additional support for overseas Japanese educational institutions over the past few decades (Gaimusho); artificiality of any sort cannot be endowed with perfection. The governmental effort was accompanied by the pains, which official and private organizations and individuals at home and abroad have taken in arranging a better educational environment for overseas Japanese children (Kaigaai de manabu Nihon no kodomo, 2017, p. 7). Nevertheless, supplementary schools have still been struggling with chronic problems and new challenges, which this article has categorized into three terms - insufficiency, instability, and inconsistency.

\section{Insufficiency}

Many of the chronic problems supplementary schools are confronted with can be understood in the context of insufficiency, and the most notable one, especially in comparison to full-time Japanese schools, is above all the insufficiency of teaching staff, including those in managerial positions such as principals and vice-principals. Regardless of their school sizes, it is by no means easy to find the teaching staff. Parents prefer to employ those who have a Japanese teaching certificate with actual teaching experience in Japan. Even without teaching experience, they tend to consider that those who have the certificate would be better than unlicensed amateurs. It is not, however, easy to find such personnel overseas. In the first place, generally speaking, smaller supplementary schools are located in areas whose Japanese population density are low and therefore would not be able to find enough applicants for open teaching positions. No matter what job qualifications, including a Japanese teaching certificate, he/she has, schools cannot employ those legally ineligible to work in the countries where they are located (Kikyusen, 2006, p. 201). Legal eligibility would furthermore not guarantee qualification for being a good teacher. Even 
The Japanese government has not been passive towards or unaware of the hardship which the overseas schools have been faced with. Since 1962, MEXT has been dispatching certified teachers who work for domestic public schools abroad (CLARINET). As of April 2016, 1,084 dispatched teachers are teaching or managing full-time or supplementary schools overseas (Kaigai de manabu Nihon no kodomo, 2016, p. 5). MEXT considers that these teachers should account for up 80 per cent of the teaching staff of each Japanese school (Kikyusen, 2012, p. 231). In 2007, MEXT introduced another dispatch system called the senior teacher dispatch system (shinia kyoin haken seido) and has been sending retired teachers who are in principle over 65 years old, and who have had more than 10 years of retirement (Kikyusen, 2007, p. 213). The Overseas Educational Services (Kaigai Shijo Kyoiku Shinko Zaidan, JOES) have also been contributing to dispatching teachers overseas. JOES is a non-profit foundation approved by MEXT and MOFA, and was established in1971 with the support of Japanese corporations for the sake of the promotion of education for overseas Japanese children in accordance with the governmental overseas educational policy (Kaigai Shijo Kyoiku Shinko Zaidan).

Similarly full-time schools, supplementary schools certainly enjoy the benefits of the dispatch systems, but not all of them. JOES has advertised for and dispatched kindergarten, elementary and junior high school teachers overseas since 2001, but only full-time Japanese schools can benefit from this system (Kaigai Shijo Kyoiku Shinko Zaidan). Putting emphasis on human resources development as a crucial part of state strategy, the Abe Cabinet and his ruling party, the Liberal Democratic Party, have obviously been paying more attention to education for overseas Japanese children (Kaigi no gaiyo, 2017, p. 5). The number of teachers dispatched by MEXT has been slightly recovering in recent few years after years of consistent decline, though it is unknown whether it is a result of the government's changing stance. (Kaigi no gaiyo, 2017, p. 5). However, a disproportion of the supply-demand balance seems to remain between the number of dispatched teachers and the number of teachers in Japanese schools overseas, including supplementary ones (Kaigi no gaiyo, 2017, p. 6-7). In order to be eligible to receive certified teachers by MEXT, supplementary schools have to have at least more than 100 students in just their elementary and junior high school programs. An additional teacher would be dispatched only in the schools whose enrollment exceeds 400, and 100 more students would be necessary to receive one more (Kaigai de manabu Nihon no kodomo, 2016, p. 5).

Supplementary schools are not sufficiently satisfied with the dispatch systems. The duties which MEXT gives to the teachers dispatched to supplementary schools are limited. They are assigned to teach in full-time schools, while they are not assigned not to teach but to be school managers as principals or vice-principals in supplementary schools (CLARINET). For supplementary schools with over an enrollment rate exceeding 100 students, it is certainly a privilege to receive an experienced professional teacher. The dispatch system does not however release them from the painstaking task of securing teaching staff locally, although it goes without saying that for smaller schools with less than 100 students, it would be a point of envy to be able to receive professional teachers from Japan. Smaller supplementary schools tend to be located in the areas which have smaller Japanese populations and would have more difficulties finding not only teachers but also school managers. The senior teacher dispatch system does not necessarily seem to be popular among some or the majority of supplementary schools, especially in terms of the quality of senior teachers (Kaigi no gaiyo, 2017, p. 6-7). There should be no doubt that those retired teachers have enough teaching and administrative experience at home and overseas, but their teaching and management know-how as principals or vice principals might be obsolete or unfortunately unfit for the schools to which they were transferred. 
The meaning of the "insufficiency" of the teaching staff should be interpreted, not merely in a numerical sense, but also in a qualitative sense. As mentioned above, among supplementary schools, there seem to be critical voices against the quality of senior dispatched teachers. However, the greatest cause of parents' dissatisfaction with supplementary schools is the quality of teaching (Kaigi no gaiyo, 2017, p. 6). The majority of the locally-employed teachers are not licensed, or licensed but inexperienced, including young graduate and undergraduate students and the Japanese women who married local non-Japanese men. The lack of a teaching certificate or teaching experience could inevitably lead to poor teaching performance in class. The possession of a Japanese teaching certificate, with or without actual teaching experience in Japan, would also not guarantee that a certified person is suitable for a school environment which is different from that at home (Kaigai Shijo Kyoiku Shinko Zaidan).

The quality (or suitability) issue does not necessarily have to be only about locally-employed teachers. The experiences and skills of the dispatched teachers, who passed the MEXT screening process, might not function in the particular environment of supplementary schools overseas. An insufficient understanding of (blindness to) the local circumstances, including overseas Japanese kids' daily life on weekdays, and an unconditional (or inflexible) application of Japanese domestic school know-how and practices might rather engender consequences which none, including the dispatched teachers themselves, desired (Kaigai Shijo Kyiku Shinko Zaidan). Respecting the authority of a Japanese teaching certificate and teaching experience, local Japanese residents never stop wishing for teachers dispatched by MEXT from Japan. If, however, the dispatched professionals should fail to be sensitive to the local circumstances and demands, the overseas residents' expectations of them could turn out to be disappointment and dissatisfaction sooner or later. As an example, one of the worst cases perhaps, was one teacher who was sent back to Japan before the expiration of his term of appointment in the Midwest of the United States in the 1990s (Kikuchi, 2003).

Dispatched teachers' term of appointment might also be insufficient. MEXT regulates that the employment period in both Japanese and the supplementary schools is two years in principle, but can be extended to up to four years. Most of the teachers spend three years, as MEXT actually expects (CLARINET). The seniors' term of employment is two years in principle, but can be extended to three years (CLARINET). Regarding this MEXT regulation, a dispatched teacher noted after returning to Japan, a few years would not be enough to become familiar with the local conditions. In consideration of the possible amount of time they would have to spend to arrange a variety of things after their arrival at their post; the first year would be a period of both physical and mental adjustment for themselves and their family to a strange environment. What (necessary for overseas schools) could be then done in the remaining two years might leave room for reconsideration

\section{Instability}

Insufficiency is closely linked with another problem, namely instability. The fixity (or retention rate) of the locally-employed teaching staff is in fact a widely shared problem among supplementary schools. Many teachers employed through local searches are female and either permanent residents or citizens in the countries where the schools are located. Since they have their own routines, teaching on the weekend would become a mere extra physical and mental burden on them. Confronted with parents' low evaluation of their teaching or not rewarded enough, they would quit the schools without hesitation even in the middle of a term.

The management of supplementary schools is not necessarily grounded on affluent and stable fiscal resources. MEXT and MOFA's annual subsidies are the pillars of school finance, and tuition is the other (Kaigai Shijo Kyoiku Shinko Zaidan; Kikyusen, 2007, p. 210). However, student enrollment does not remain stable and could fluctuate according to 
given conditions, especially local and international economy. For example, the financial crisis following the bankruptcy of the Lehman Brothers in the fall of 2008 hit the enrollment of both full-time and supplementary schools in the United States. Financial toughness (or weakness) differs among supplementary schools. Some schools are in better financial positions as they regularly or irregularly receive donations, or are supported by the membership fees of local Japanese business and residential organizations (Yamane, 2010). However, non-tuition revenue is also subject to any given changeable conditions. To make matters worse, the governmental budget for overseas education had gone through constant cutbacks in the midst of the unpredictably critical Japanese fiscal conditions for years since the first decade of this century until very recently (Kikyusen, 2008, p. 217, 223, 2008; 2010, p. 213; 2011, p. 228; Kaigai zairyu hojinsu chosa tokei, 2017, p. 5).

Because of insufficient fiscal resources, most supplementary schools cannot afford to have their own school buildings and sites, to which the instability of the schools is ascribed. Most supplementary schools in fact have to rent buildings and rooms from local schools. The rent of local school buildings and rooms is not necessarily inexpensive and poses a serious burden on school finances (Hoshuko, 2005). For example, in the case of the United States, rent income usually goes to the local board of education and seldom benefits the local schools and teachers directly. Minor incidents over the damage of school facilities and the loss of personal or school belongings are more or less routines in the leased school facilities. Having no alternative unless they rent local school facilities, supplementary schools in a weaker position have to take the blame from local schools regardless of whether they are guilty or not. Japanese schools, parents, and even children, are not therefore free from a sense of insecurity (or instability) over the survival of the school.

\section{Inconsistency}

The insufficiency found in the different aspects of supplementary schools could lead to inconsistency in faculty rooms and classrooms. Those teachers go abroad without enough knowledge of their posts, and are replaced every few years without enough time to accumulate enough know-hows of overseas education. Such frequent turnover of the dispatched teachers would cause frequent changes to school guidelines and policies, which could cause confusion, misunderstanding and errors easily (Kaigai Shijo Kyoiku Shinko Zaidan). The senior dispatch system would certainly be a help to the shortage of dispatched teachers, but dispatched senior teachers' health conditions, along with their short term of appointment, might become another cause of inconsistency (and instability) in school management. JOES holds a conference for the executive members of the (Japanese and supplementary) school secretariat in the summer every two years in Tokyo. In 2011, a couple of attendees expressed their concern over senior teachers' lack of physical strength to take charge of school administration in a strange land (Kaigai Shijo Kyoiku Shinko Zaidan). MEXT also acknowledges the case that a senior teacher experienced health problems during his term of appointment and was sent back to Japan (Kikyusen, 2008, p. 213).

All causes of inconsistency should not, however, be fully forced on the dispatched teachers. The turnover of the members of the steering committees occurs frequently also. Most of the members are the students' parents who are either expatriates from Japanese companies or locally or self-employed legal residents, and each member spends a few or several years to serve on the committee (Kaigai Shijo Kyoiku Shinko Zaidan; Yamashita, 2009). Furthermore, the turnover of the locally-employed teaching staff at the end or even in the middle of the academic year is almost a routine event in supplementary schools. Such frequent turnover of teachers makes it difficult for supplementary schools to provide quality education and to win parents' trust. 


\section{CONCLUSIONS}

Supplementary schools have been spreading all over the world for the past half a century in parallel with Japanese business expansion overseas, and have played a vital role in Japanese overseas education, along with full-time Japanese schools. It would not be an exaggeration that the current state of overseas Japanese education is a result of the collaboration between the Japanese government -- MEXT and MOFA - and Japanese organizations and individuals at home and abroad. Despite official and non-official efforts and mutual collaboration, nevertheless, supplementary schools have faced various and even chronic problems. The Japanese government seems to be aware of the challenges facing the overseas educational institutions for Japanese children. Director, International Education Division, Nakai Kazuhiro stated, in the early summer of 1212, a few months before his return to MOFA that Japanese overseas education was at the crossroads (Kikyusen, 2012, p. 230). Five years before then, another MXT official noted that confronted with complicated circumstances outside and inside themselves, supplementary schools were in a transitional period (Kikyusen, 2007, p. 210). The Abe Cabinet has been paying more attention to overseas education from a strategic point of view and related budget, yet it may still be premature to predict what the future would hold for supplementary schools.

\section{REFERENCES}

1 Chicago Futabakai Nihongo Gakko. (n. d.). Retrieved April 29, 2013, from http://www.chicagojs.com/

2 CLARINET e yokoso. (n. d.). Retrieved April 25, 2013, from http://www.mext.go.jp/a menu/shotou/clarinet/main7 a2.htm

3 Gaimusho. (n. d.). Retrieved April. 25, 2013, from http://www.mofa.go.jp/mofaj/

4 “Hoshuko no shoraizo o kentosuru iinkai (kasho)” hokokusho. (2005). Retrieved May 1, 2013, from http://hitoshi.ipmu.jp/misc/draft5.doc

5 Japanese School New Delhi. (n. d.). Retrieved December 15, 2017, from http://ndjs.org/\%e5\%85\%a5\%e5\%ad\%a6\%e9\%87\%91\%e7\%ad\%89/.

6 Japanese School of New York. (n. d.). Retrieved December 15, 2017, from http://www.gwjs.org/wpcontent/uploads/2017/11/2018.

7 Ariel P. Tuazon et al.,, School Practices in Parental Involvement, Its Expected Results \& Barriers in Public Secondary Schools, International Journal of Educational Science and Research (IJESR), Volume 6, Issue 1, January - February 2016, pp. 59-78

8 Kaigai de Manabu Nihon no kodomotachi. (2016). Retrieved November 27, 2017, from http://www.mext.go.jp/a menu/shotou/clarinet/002/001.htm

9 Kaigai Shijo Kyoiku Shinko Zaidan. (n. d.). Retrieved from April 27, 2013, from http://www.google.co.jp/\#output=search\&sclient (2017) "Kaigi no gaiyo." Retrieved from December 10, 2017, from http://www.joes.or.jp/cms/joes/pdf/zaigai/jimucho/2017kaigigaiyo.pdf

10 Kaigai zairyu hojinsu chosa tokei (Heisei 29-nendo sokuhoban). (2017). Tokyo: Gaimusho Ryojikyoku Seisakuka.

11 Keio Academy of New York. (n. d.). Retrieved December 13, 2017, from http://www.keio.edu/page.cfm?p=578.

12 Kikoku shijo kyoikuni kansuru anketo” chosa kekka ni tsuite. (2008). Kokuritsu Tokubetsu Shien Kyoiku Sogo Kenkyujo, kyiku kenkyu nenpo, 29, 35-48.

13 Albiya I. Dagbusan, Organization and Management of Resources for Guidance Program Development of Secondary Schools in Bongao, Tawi-Tawi, International Journal of Educational Science and Research (IJESR), Volume 7, Issue 1, January - 
February 2017, pp. 183-194

14 Kikyusen: kaigaai shojo kyoiku daayori. (n. d.) Tokyo: Monbu Kagakusho Shoto Chuto Kyoikukyoku Kokusai Kyoikuka. Mombu Kagakusho. (n.d.). Retrievd April 23, 2013, from http://www.mext.go.jp/

15 Nihonkoku kenpo no tanjo. (n. d.). Retrieved December 10, 2017, from http://www.ndl.go.jp/constitution/etc/j01.html\#s3.

16 Rosu Anjerusu Nihonkoku Soryojikan. (n. d.). Retrieved May 5, 2013, from http://www.la.us.embjapan.go.jp/web/m04_01_02.htm

17 Sasaki Tsukasa \& Ishikawa Akira. (2008) “Wagakuni ni okeru kokusai jiko ido no doko to shorai suikei jinko eno eikyo,” Jinko mondai kenkyu, 64-4, 1-18.

18 Suenaga Kazuhiko. (2017). "Junzennichisei hoshu jigyoko no kyoiku." Retrieved December 13, 2017, from http://www.libsato.justhpbs.jp/H27kikokuhoukoku/H27kikokuhoukoku-suenaga.pdf.

19 Waseda Shibuya Senior High School in Singapore. (n. d.). Retrieved December 15, 2017, http://www.waseda-shibuya.edu.sg/eexamination05.php.

20 Yamane Takeshi. (2010) Zairyu hojin no Berugi deno kyoiku, seikatsu ni kansuru genjo to kadai: ishiki chosa, gakko hyoka o toshite. Zaigai kyiku shisetsu ni okeru shido jissen kiroku, 33, 201-205.

21 Yamashita Hisakazu. (2009). "Hoshu Jugyoko ni okeru kyoiku to keiei no aarikata. Zaigai kyiku shisetsu ni okeru shido jissen kiroku, 31, 243-246. 